\title{
Tensile Properties and Reinforcement Mechanisms of Natural Rubber/Vapor-Grown Carbon Nanofiber Composite Hong-Xia Jiang ${ }^{1}$, Qing-Qing $\mathrm{Ni}^{2}$, Toshiaki Natsuki ${ }^{1}$ \\ ${ }^{1}$ Faculty of Textile Science \& Technology, Shinshu University, Ueda, Japan \\ ${ }^{2 a}$ Key Laboratory of Advanced Textile Materials and Manufacturing Technology Ministry of Education, Zhejiang Sci-Tech University, Hangzhou 310018, P.R. China \\ ${ }^{2 b}$ Faculty of Textile Science \& Technology, Shinshu University, Ueda, Japan
}

\begin{abstract}
Natural rubber (NR) composites with different contents of 1, 3, 10 and $20 \mathrm{wt} \%$ vapor-grown carbon nanofibers (VGCFs) were synthesized using a solvent casting method. The initial modulus of composites was improved by $26.5 \% / \mathrm{wt} \%$ as the VGCFs were added, and the NR/3wt\% VGCF composite had the largest tensile strength. The experiment values of initial moduli agreed well with the values predicted by the Halpin-Tsai theory. The reinforcement mechanisms of the composites were investigated by scanning electron microscopy (SEM), Fourier transform infrared (FT-IR) spectroscopy and wide-angle X-ray diffraction (WAXD). It was found that an efficient stress transfer occurred from NR to VGCFs under the uniaxial stretching. The addition of $10 \mathrm{wt} \%$ VGCFs could promote the nucleation process of NR, which resulted in the characteristic of the strain-induced crystallization (SIC) in NR/10wt\%VGCF composite even for low strain.
\end{abstract}

\section{INTRODUCTION}

The innovative performance of rubber materials has become very important in recent years for its energy dissipation, which people expect to be efficiently used in energy storage devices such as mechanical energy batteries and regenerative brake devices as reported by Arun Raman and Richard J. Farris [1-2]. In the various rubber materials, the natural rubber (NR) is widely used in the rubber industry, not only for its compatibility with fillers but also for its high tensile strength, a result of its outstanding strain-induced crystallization (SIC) [3-8]. A. N. Gent and L.-Q. Zhang [3-4] have studied the nonlinear increment of NR strength and found that the higher strength of NR was attributed to more strain-induced crystallinity occurred during tensile deformation. The effects of various fillers, such as carbon black, silica, clay and silicate, on the mechanical properties and the reinforcement mechanism of NR composites have been also investigated [9-15]. Wu et al. [11] have proved that the modulus of NR/fluorohectorite nanocomposites was increased by the addition of 10 parts per hundred rubber (phr) fluorohectorite, while the tensile strength decreased due to fluorohectorite's hindrance on NR crystallization. Wang et al. [14-15] have found that the tensile strength of $\mathrm{NR} /$ rectorite and NR/clay composites stopped increasing when the filler content was larger than $10 \mathrm{wt} \%$ because of its impediment to SIC behavior of NR. The tensile properties of the NR composites have been demonstrated to depend greatly on both filler type and content.

Recently, carbon nanotubes (CNTs) have attracted great interest in many engineering applications for their high tensile strength and high aspect ratio. There are many studies [16-21] on the mechanical properties of polymer composites filled with CNTs, but few studies focus on NR/CNT composites. Kueseng and Jacob [22] have fabricated natural rubber/single-walled carbon nanotube (NR/SWCNT) composites and have investigated 
their mechanical properties. They found that the tensile strength of NR/SWCNT composites increased due to the addition of just $1.5 \mathrm{wt} \%$ CNTs into the NR matrix. Fakhru'l-Razi et al. [23] have developed NR composites filled with multi-walled carbon nanotubes (MWCNTs). The result showed that the stress value of the NR/MWCNT composites with $10 \mathrm{wt} \%$ MWCNT content increased by 9 times compared to that of pure NR. However, they did not address the microscopic behaviors of NR/CNT composites, especially on the SIC behavior of vulcanized NR, which is crucial to the macro-mechanical properties of natural rubber composites. As it becomes progressively more possible to produce the CNTs by various chemical vapor deposition (CVD) methods at low cost, CNTs could be a powerful candidate in rubber industry.

In this study, we selected vapor-grown carbon nanofibers (VGCFs) as the reinforcement filler. The NR composites with different contents of 1, 3, 10 and $20 \mathrm{wt} \%$ VGCFs were synthesized using a solvent casting method. Our aims were to develop a new NR composite reinforced by VGCFs, and to illustrate the reinforcement mechanism by investigating its microscopic behaviors, especially by the SIC behavior of NR/VGCF composites.

\section{EXPERIMENTAL}

\section{Sample preparation}

To prepare the composite materials, NR gum (Sumitomo Rubber Co. Ltd., Japan) and untreated VGCFs (Showa Denko Co. Ltd., Japan) were used as raw materials. The untreated VGCFs have a diameter of around $150 \mathrm{~nm}$ and a length of about $10-20 \mu \mathrm{m}$. As per a report by Kueseng and Jacob [22], the fabrication of NR/VGCF composites was divided into the following steps in this study. Firstly, VGCFs $(10 \mathrm{mg} / \mathrm{ml})$ with contents of $1,3,10$ and $20 \mathrm{wt} \%$ were added into toluene, and were well dispersed by ultrasonic stirring at room temperature for $2 \mathrm{~h}$, respectively. NR gum $(50 \mathrm{mg} / \mathrm{ml})$ was also dissolved into toluene in a separate beaker. Secondly, vulcanizing agents, VGCF solution and NR solution were mixed and stirred for $1 \mathrm{~h}$. Thirdly, the solvent was evaporated off at $50{ }^{\circ} \mathrm{C}$ for approximately 2 days in vacuo. Finally, the vulcanization was carried out at $160{ }^{\circ} \mathrm{C}$ for $15 \mathrm{~min}$ using a hot press. NR/VGCF composite sheets with a thickness of $1 \mathrm{~mm}$ were fabricated. The compositions of NR material used in the study are listed in Table 1.

\section{Characterization}

The tensile properties of the samples were attained referring to JIS $\mathrm{K} 5012$ by a TENSILON RTC-1250A mode tensile instrument (A\&D Co., Japan). Tensile tests were performed on dumbbell-shaped samples at a crosshead speed of $100 \mathrm{~mm} / \mathrm{min}$ at room temperature and 50-60\% humidity. Five samples of each material were tested.

The dispersion and alignment morphologies of VGCFs in NR, before and after stretching, were examined with a Hitachi S-3400N mode scanning electron microscopy (SEM) at an accelerator voltage of $20 \mathrm{kV}$. The samples observed by SEM were coated with Pt-Pd sputtering.

To obtain a deeper insight into the interaction between VGCFs and NR, Fourier transform infrared spectroscopy (FT-IR) measurements were conducted in the attenuated total reflection mode (ATR) by using an IR Prestige-21 spectrometer (Shimadzu, Japan). The FT-IR spectra were obtained in transmission mode at an average of 100 scans and a resolution of $4 \mathrm{~cm}^{-1}$.

Based on wide-angle X-ray diffraction (WAXD), the SIC behaviors of NR composites were investigated by a Rigaku Geigerflex 2028 diffractometer (Rigaku, 
Japan) with $\mathrm{Ni}$-filtered $\mathrm{CuK} \alpha$ radiation at $40 \mathrm{kV}$ voltage and $150 \mathrm{~mA}$ current. The X-ray diffractions of the samples were obtained by sequential measurement, in which the samples were drawn uniaxially to different strain levels and then were scanned at a rate of $2 \% \mathrm{~min}$ and within the range of $2 \theta<30^{\circ}$.

\section{RESULTS AND DISCUSSION}

Mechanical properties.

Figure 1 shows the stress-strain curves of NR/VGCF composites with different VGCF contents. All of the curves have turning points and their scopes increase shapely with a typical nonlinear behavior in the tensile process. This indicates that the resistance of the developed NR materials against the deformation depends on the tensile process, and this may be attributed to strain-induced crystallization (SIC) as many researchers have reported [3-8]. In the low strain region, the initial modulus is low and slowly increases with increasing strain. When the strain arrives to a certain value, the stress increases sharply because the tensile crystallization occurs in the tensile process. The turning point of strain obtained through drawing two tangent lines along the curves in a very steep region, is about 2.0 for the NR/10wt\%VGCF composite in contrast with about 4.0 for the NR material. The stress of NR/10wt\%VGCF composite at the strain $\varepsilon$ $=2.0$ is about 2.5 times as large as that of NR composite, and about 5.0 times at $\varepsilon=4.0$. Considering this improved SIC behavior, it can be presumed that NR macromolecules were rearranged at low strain by blending them with the appropriate VGCFs. The investigation results of the microstructure of NR/VGCF composites are to be discussed in the following sections.

For the reinforcement of CNT filler on mechanical properties, the tensile strength of composites is found to increases with the increment in VGCF content. Compared with the pure NR material, the NR/VGCF composites show the higher deformation resistance. When VGCF content is up to $3 \mathrm{wt} \%$, the composite exhibits the largest tensile strength. The initial modulus of composites increases linearly with the addition of VGCF content. Table 2 summarizes the initial modulus, strain at break, stress at 2.0 strain, stress at 4.0 strain and stress at breakage for each composite material. The initial modulus of composites is radically improved by $26.5 \% / \mathrm{wt} \%$ as VGCFs are added. It is interesting that the VGCFs reinforcement ratio is almost constant. This implies that VGCFs were distributed uniformly into NR matrix and the force transfer from NR to VGCFs was linearly increased with the VGCF content up to $20 \mathrm{wt} \%$ in the developed materials.

To prove the reinforcement efficiency of VGCFs, the well- known Halpin-Tsai theory is used to simulate the modulus of NR/VGCF composites. Taking account of the moduli of the two phases and the aspect ratio of the filler, the modulus of NR composites with randomly distributed VGCF is given by

$$
\begin{aligned}
& E_{c}=E_{m}\left[\frac{3}{8} \cdot \frac{1+2 f \eta_{L} c}{1-\eta_{L} c}+\frac{5}{8} \cdot \frac{1+2 \eta_{T} c}{1-\eta_{T} c}\right] \\
& \eta_{L}=\frac{\left(\frac{E_{V G C F}}{E_{m}}\right)-1}{\left(\frac{E_{V G C F}}{E_{m}}\right)+2 f}, \quad \eta_{T}=\frac{\left(\frac{E_{V G C F}}{E_{m}}\right)-1}{\left(\frac{E_{V G C F}}{E_{m}}\right)+2}
\end{aligned}
$$


where $f$ is the aspect ratio of VGCFs, $c$ is the volume fraction of VGCFs, and $E_{V G C F}$ and $E_{m}$ are the moduli of VGCFs and NR composite, respectively.

In this simulation, $E_{V G C F}$ is $200 \mathrm{GPa}, E_{m}$ is $0.85 \mathrm{MPa}$ and $f$ is taken as 75 . For a content of less than $20 \mathrm{wt} \%$, as shown in Fig. 2, the measured modulus agrees well with the value predicted by the Halpin-Tsai theory. This implies that a good interface was formed between the two phases because the Halpin-Tsai theory is based on perfect interface. The Halpin-Tsai theory can be used well to predict the modulus of NR/VGCF composites.

\section{Morphology of NR/VGCF composites}

Figure 3 shows the fracture profiles of NR/VGCF samples sliced with a razor cut before the tensile test. It is observed that VGCFs were dispersed randomly and evenly into NR except for a little aggregation observed in the NR/20wt\%VGCF sample. The good dispersion, which is essential to the formation of the immobilized polymer surrounding the embedded VGCFs [18], is due to the surface free energy of VGCFs reduced by ultrasonication stirring. Fig. 4 shows the fracture profile of a NR/10wt\%VGCF sample after the tensile test. Ductile patterns of NR matrix were observed on the surface of VGCFs, which were well embedded in the NR and some of which fractured when the sample was broken. Moreover, the VGCFs were oriented relative to the SIC of NR along the stretching direction. These characteristics indicate that an immobilized polymer layer between NR and VGCFs was obtained after the vulcanization process. This is also supported by the good agreement between experimental results and the Halpin-Tsai theory as stated in the previous section.

FT-IR spectroscopy

The variations of the FT-IR wavenumbers of the NR/VGCF composites under uniaxial stretching were investigated. Figure 5 shows the FT-IR spectra of $\mathrm{NR} / 10 \mathrm{wt} \% \mathrm{VGCF}$ composites at strain $\varepsilon=0, \varepsilon=2.0$ and $\varepsilon=4.0$. The $\mathrm{C}-\mathrm{H}$ bend bands of $-\mathrm{C}\left(\mathrm{CH}_{3}\right)=\mathrm{CH}$ - group, $\mathrm{CH}_{3}$ - group and $\mathrm{CH}_{2^{-}}$group [24-26] shift to higher wavenumbers when the samples are stretched, which agrees with the results reported by Liliane Bokobza [26]. The detailed investigation of the wavenumbers of the $\mathrm{C}-\mathrm{H}$ bend band of the $-\mathrm{C}\left(\mathrm{CH}_{3}\right)=\mathrm{CH}$ - group as a function of strain is shown in Fig. 6. No spectra were obtained for NR/20wt\%VGCF composite because $20 \mathrm{wt} \%$ VGCFs exceed the absorption saturation of infrared ray. The wavenumber of the $\mathrm{C}-\mathrm{H}$ bend band for the $-\mathrm{C}\left(\mathrm{CH}_{3}\right)=\mathrm{CH}$ - group shifts from $833 \mathrm{~cm}^{-1}$ to a lower wavenumber with increasing VGCF content, to $825 \mathrm{~cm}^{-1}$ in the NR/3wt\%VGCF composite and $823 \mathrm{~cm}^{-1}$ in the $\mathrm{NR} / 10 \mathrm{wt} \%$ VGCF composite. The wavenumbers of the $\mathrm{C}-\mathrm{H}$ bend band increase when the samples are stretched, and the wavenumber increment in the NR/10wt\%VGCF composite is the most significant. There is a steeper shift rate of $0.035 \mathrm{~cm}^{-1} / \%$ in the NR/10wt\%VGCF composite compared with $0.02 \mathrm{~cm}^{-1} / \%$ in the NR/3wt\%VGCF composite and $0.01 \mathrm{~cm}^{-1} / \%$ in the NR composite.

Molecular vibrations can be treated using Newtonian mechanics to calculate the vibration frequencies (and hence the wavenumber). The following expression is derived from Hooke's law and Newton's second law of motion and is well used for diatomic bonds. The wavenumber of the band is given by

$$
k=\frac{1}{2 \pi c} \sqrt{\frac{F}{m}}
$$

where $k$ is the wavenumber of the band, $c$ is the velocity of light, $F$ is the force constant of the bond and $m$ is the reduced mass.

Combining the trend of results with Eq. 2, the following conclusions could be drawn: 
In the NR/VGCF composites, the bending strength of $\mathrm{C}-\mathrm{H}$ bond became progressively weaker with an increase in VGCF content because the out-of-plane vibration of the $\mathrm{C}-\mathrm{H}$ bond was inhibited by randomly and evenly dispersed VGCFs, which suggests that the internal stress induced by the vulcanization process transferred from NR matrix to VGCFs. Moreover, the bending strength of $\mathrm{C}-\mathrm{H}$ bond in NR/VGCF composites increased with increasing strain, which is most significant in NR/10wt\% VGCF composite. This is because that an efficient stress transfer occurred when the NR/VGCF composites were stretched and a stronger orientation of polymer chains induced by the aligned VGCF bundles.

$X R D$ analysis

The effects of VGCFs on the SIC behavior of NR composites were investigated by XRD analysis. Figure 7 shows the X-ray diffraction patterns of NR, NR/3wt\%VGCF, NR/10wt\%VGCF and NR/20wt\%VGCF composites at different strains. In Fig. 7(a), before stretching, the diffraction spectra in the NR/VGCF composites are mainly dominated by the $(002)$ peak at about $2 \theta=26.1^{\circ}$ corresponding to interlayer spacing of VGCFs [19, 27]. Additionally, the amorphous pattern of NR becomes progressively weaker as the content of VGCFs increases, and finally shows a low broad halo for the NR/20wt\%VGCF composite. In Fig. 7(b), when stretching to $\varepsilon=2.0$, the (200) peak of $\mathrm{NR}$ at about $2 \theta=14.1^{\circ}$ [28] is observed in the case of NR/10wt\%VGCF and $\mathrm{NR} / 20 \mathrm{wt} \%$ VGCF composites while there are no changes in the others, and the (002) peak of VGCFs becomes sharper and stronger in VGCFs-reinforced NR composites. In Fig. 7(c), when stretching to $\varepsilon=4.0$ the (200) peak of NR is observed in all of the diffraction spectra, and the intensity is the largest for the NR/10wt\%VGCF composite. Additionally, the (120) peak of NR at about $2 \theta=20.7^{\circ}[28,29]$ appears in the case of $\mathrm{NR} / 10 \mathrm{wt} \% \mathrm{VGCF}$ and $\mathrm{NR} / 20 \mathrm{wt} \% \mathrm{VGCF}$ composites and its intensity in the $\mathrm{NR} / 10 \mathrm{wt} \% \mathrm{VGCF}$ composite is much stronger than that in the NR/20wt\%VGCF composite due to the lower NR content in NR/20wt\%VGCF composite. The weakened amorphous pattern of NR indicates that much more VGCFs were evenly intercalated into NR macromolecules as the content of VGCFs increased, which was indispensable in the formation of a good interface between the two phases. The SIC behavior of $\mathrm{NR} / 10 \mathrm{wt} \% \mathrm{VGCF}$ composite occurred at lower strain due to the stronger orientation of the polymer chains. It could be deduced that the appropriate amount of $10 \mathrm{wt} \%$ VGCFs promoted the nucleation process of NR when stretching the composite. Combining this deduction with the enhanced tensile properties, we can conclude that the nucleation process of NR accelerated by VGCFs will also have an important contribution to the reinforcement mechanism of the NR/VGCF composites.

\section{CONCLUSIONS}

NR/VGCF composites with filler contents up to $20 \mathrm{wt} \%$ were fabricated using a solvent casting method. The tensile strength of composites increased with the increment in VGCF content and the large reinforcement effect and deformation resistance of VGCFs on NR matrix were obtained in the developed composites due to the uniform distribution of VGCF fillers and strain-induced crystallization occurred during tensile deformation. The initial modulus increased constantly by about $26.5 \% / \mathrm{wt} \%$ with increasing VGCF content. The tensile strength of NR/10wt\% VGCF composite at 2.0 strain was about 2.5 times as large as that of NR composite, and about 5.0 times at 4.0 strain. The NR/3wt\%VGCF composite had the greatest tensile strength and there may exist an optimum VGCF content for further improvement of mechanical properties. 
According to FT-IR spectroscopic analysis, a good interface between NR and VGCFs was confirmed. When NR/VGCF composites were stretched uniaxially, an efficient stress transfer occurred from NR to VGCFs and this resulted in the higher orientation of VGCFs and the occurrence of SIC behavior of NR even for low strain. This has been further confirmed by the results of XRD. Thus, we conclude that the appropriate amount of VGCFs, about $10 \mathrm{wt} \%$ in this study, can promote the nucleation process of NR polymers and can thus accelerate the SIC of NR. The nucleation process will have an important contribution to the reinforcement mechanism of the NR/CNT composites.

\section{ACKNOWLEDGMENTS}

This work was partly supported by Grant-in-Aid Global COE Program and CLUSTER (the second stage) by the Ministry of Education, Culture, Sports, Science and Technology, Japan. 


\section{REFERENCES}

1. Arun Raman and Richard J. Farris, Polym. Eng. Sci., 47, 1511 (2007).

2. Arun Raman and Richard J. Farris, Polym. Eng. Sci., 47, 1521 (2007).

3. Gent AN and Zhang LQ, Rubb. Chem. Tech., 75, 923 (2002).

4. A.N. Gent and L.Q. Zhang, J. Polym. Sci., Part B, 39, 811 (2001).

5. S. Toki, I. Sics, S. Ran, L. Liu and B.S. Hsiao, Polymer, 44, 6003 (2003).

6. M. Tosaka, Polym. J., 39, 1207 (2007).

7. M. Arroyo, M.A. Lopez-Manchado, J.L. Valentin and J. Carretero, Compos. Sci.

Technol., 67, 1330 (2007)

8. E.H. Andrews, Proc. R. Soc. Lond. A, 277, 562 (1964).

9. A. N. Gent, G. R. Hamed and W.-J. Hung, J. Adhesion, 79, 905 (2003).

10. Gent AN, Hartwell JA and Lee G, Rubb. Chem. Tech., 76, 517 (2003).

11. Y.P. Wu, Y. Ma, Y.Q. Wang and L.Q. Zhang, Macromol. Mater. Eng., 289, 890 (2004).

12. J.M. Chenal, C. Gauthier, L. Chazeau, L. Guy and Y. Bomal, Polymer, 48, 6893 (2007).

13. Y. Sun, Y. Luo and D. Jia, J. Appl. Polym. Sci., 107, 2786 (2008).

14. Y. Wang, H. Zhang, Y. Wu, J. Yang and L. Zhang, Eur. Polym. J., 41, 2776 (2005).

15. Y. Wang, H. Zhang, Y. Wu, J. Yang and L. Zhang, J. Appl. Polym. Sci., 96, 318 (2005).

16. M.K. Seo, J.R. Lee and S.J. Park, Mater. Sci. Eng. A, 404, 79 (2005).

17. Q. Zhao, R. Tannenbaum and K.I. Jacob, Carbon, 44, 1740 (2006).

18. A. Eitan, F.T. Fisher, R. Andrews, L.C. Brinson and L.S. Schadler, Compos. Sci.

Technol., 66, 1162 (2006).

19. D. Zhu, C. Xu, N. Nakura and M. Matsuo, Carbon, 40, 363 (2002).

20. Y.K. Choi, K.I. Sugimjoto, S.M. Song and M. Endo, Mater. Lett., 59, 3514 (2005).

21. T.T. Pham, V. Sridhar and J.K. Kim, Polym. Compos., 30, 121 (2009).

22. K. Kueseng and K.I. Jacob, Eur. Polym. J., 42, 220 (2006).

23. A. Fakhru'l-Razi, M. A. Atieh, N. Girun, T.G. Chuah, M. El-Sadig and D.R.A. Biak, Compos. Struct., 75, 496 (2006).

24. W.S. Richardson and A. Sacher, J. Polym. Sci., 10, 353 (1953).

25. Amiya R. Tripathy, Jeremy E. Morin, Drew E. Williams, Stephen J. Eyles and Richard J. Farris, Macromolecules, 35, 4616 (2002).

26. L. Bokobza, Polymer, 48, 4907 (2007).

27. Y. Peng and H. Liu, Ind. Eng. Chem. Res., 45, 6483 (2006).

28. S. Kohjiya, M. Tosaka, M. Furutani, Y. Ikeda, S. Toki and B.S. Hsiao, Polymer, 48, 3801 (2007).

29. S. Toki, T. Fujimaki and M. Okuyama, Polymer, 41, 5423 (2000). 


\section{Figure captions}

Fig. 1. Stress-strain curves of NR composites reinforced by different contents of VGCFs.

Fig. 2. Measured modulus versus weight VGCF content and comparison with Halpin-Tsai theory.

Fig. 3. SEM morphology of NR/VGCF composites with different VGCF contents: (a) 1 $\mathrm{wt} \%$, (b) $3 \mathrm{wt} \%$, (c) $10 \mathrm{wt} \%$ and (d) $20 \mathrm{wt} \%$.

Fig. 4. SEM morphology of NR/10 wt $\%$ VGCF composite after tensile test.

Fig. 5. FT-IR spectra of NR/10wt\% VGCF composite at strain $\varepsilon=0,2.0$ and 4.0.

Fig. 6. Wavenumbers of the $\mathrm{C}-\mathrm{H}$ bend band of the $-\mathrm{C}\left(\mathrm{CH}_{3}\right)=\mathrm{CH}-$ group of $\mathrm{NR}$, $\mathrm{NR} / 3 \mathrm{wt} \% \mathrm{VGCF}$ and NR/10wt\%VGCF composites as a function of strain.

Fig. 7. X-ray diffraction pattern of NR, NR/3wt\%VGCF, NR/10wt\%VGCF, NR/20wt\%VGCF composites: (a) at strain $\varepsilon=0$, (b) at strain $\varepsilon=2.0$ and (c) at strain $\varepsilon=4.0$. 
Table 1

NR compound formulation

\begin{tabular}{ll}
\hline Ingredients & $\mathrm{phr}^{\mathrm{a}}$ \\
\hline NR & \\
Zinc oxide & \\
Sulfur & \\
Stearic acid & 100 \\
Cyclohexyl benzothiazole sulfonamide & 5 \\
& 2 \\
& 2 \\
& 0.8
\end{tabular}

${ }^{\mathrm{a}}$ Parts per hundred rubber 
Table 2

Mechanical properties of NR composites reinforced by different contents of VGCFs

\begin{tabular}{llllll}
\hline \multirow{2}{*}{$\begin{array}{c}\text { VGCF } \\
\text { content (wt\%) }\end{array}$} & $E(\mathrm{MPa})$ & \multirow{2}{*}{$\begin{array}{l}\text { Strain } \\
\text { at break }\end{array}$} & & \multicolumn{3}{c}{ Stress (MPa) } \\
\cline { 5 - 6 } 0 & & at $\varepsilon^{\mathrm{a}=2.0}$ & at $\varepsilon=4.0$ & at break \\
\hline 1 & 0.85 & 6.97 & 0.93 & 2.29 & 18.75 \\
3 & 1.07 & 6.09 & 1.09 & 3.49 & 19.39 \\
10 & 1.81 & 5.77 & 1.51 & 5.20 & 21.07 \\
20 & 2.89 & 4.77 & 2.28 & 11.27 & 16.65 \\
& 5.35 & 4.14 & 3.21 & 13.45 & 15.76 \\
\hline
\end{tabular}

${ }^{\mathrm{a}} \varepsilon$ represents the strain 


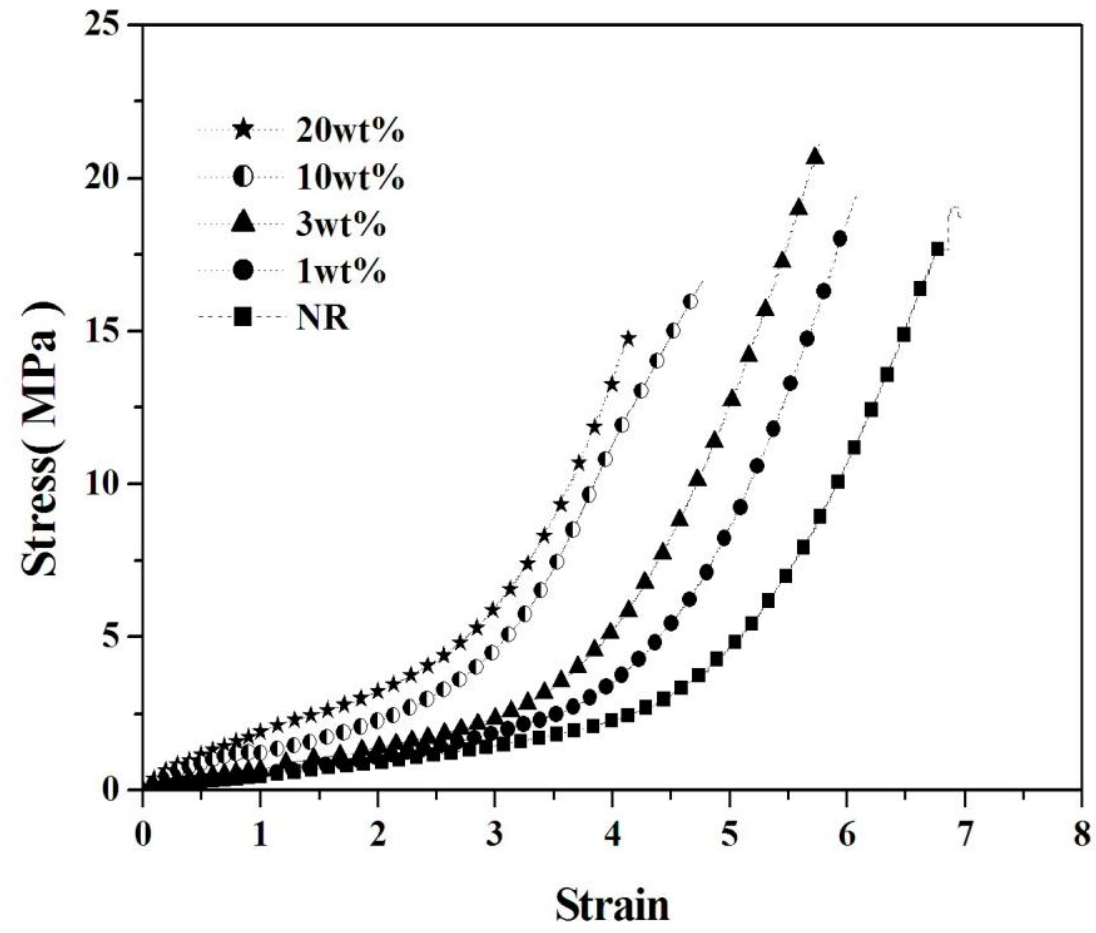

Fig. 1. 


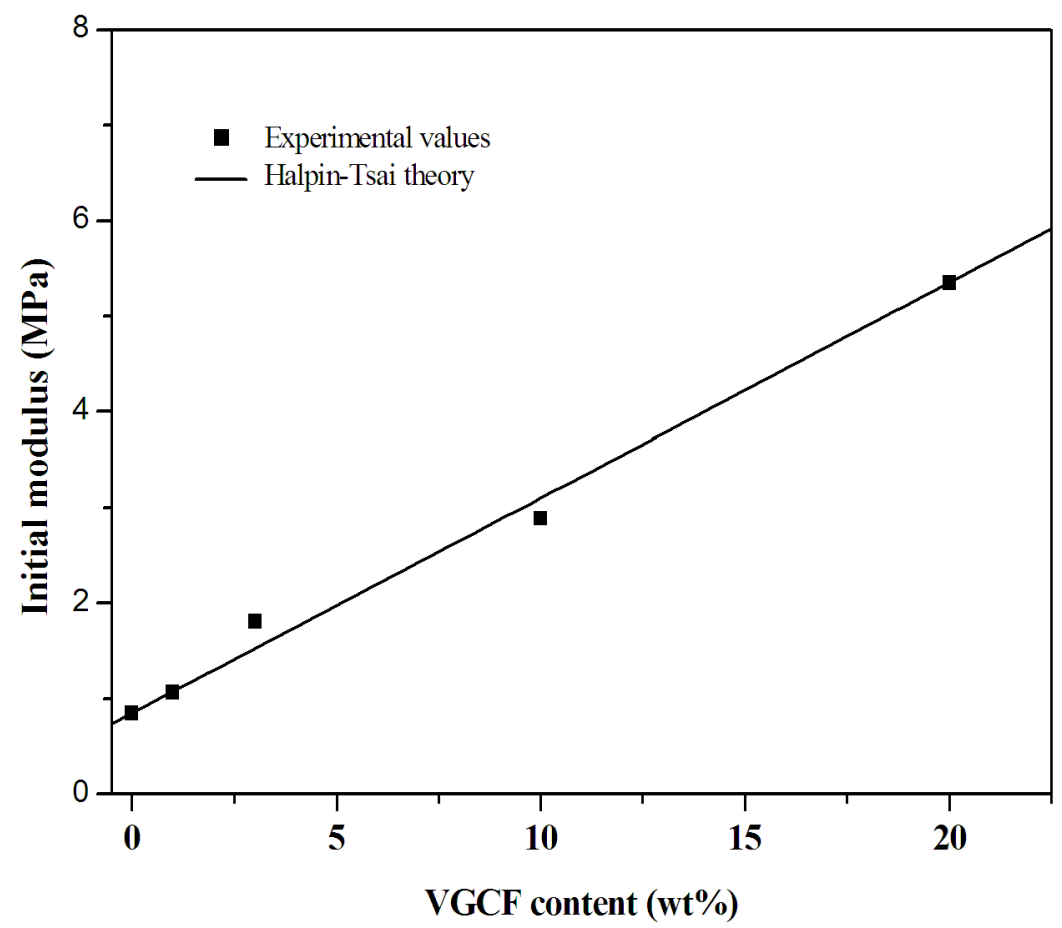

Fig. 2. 

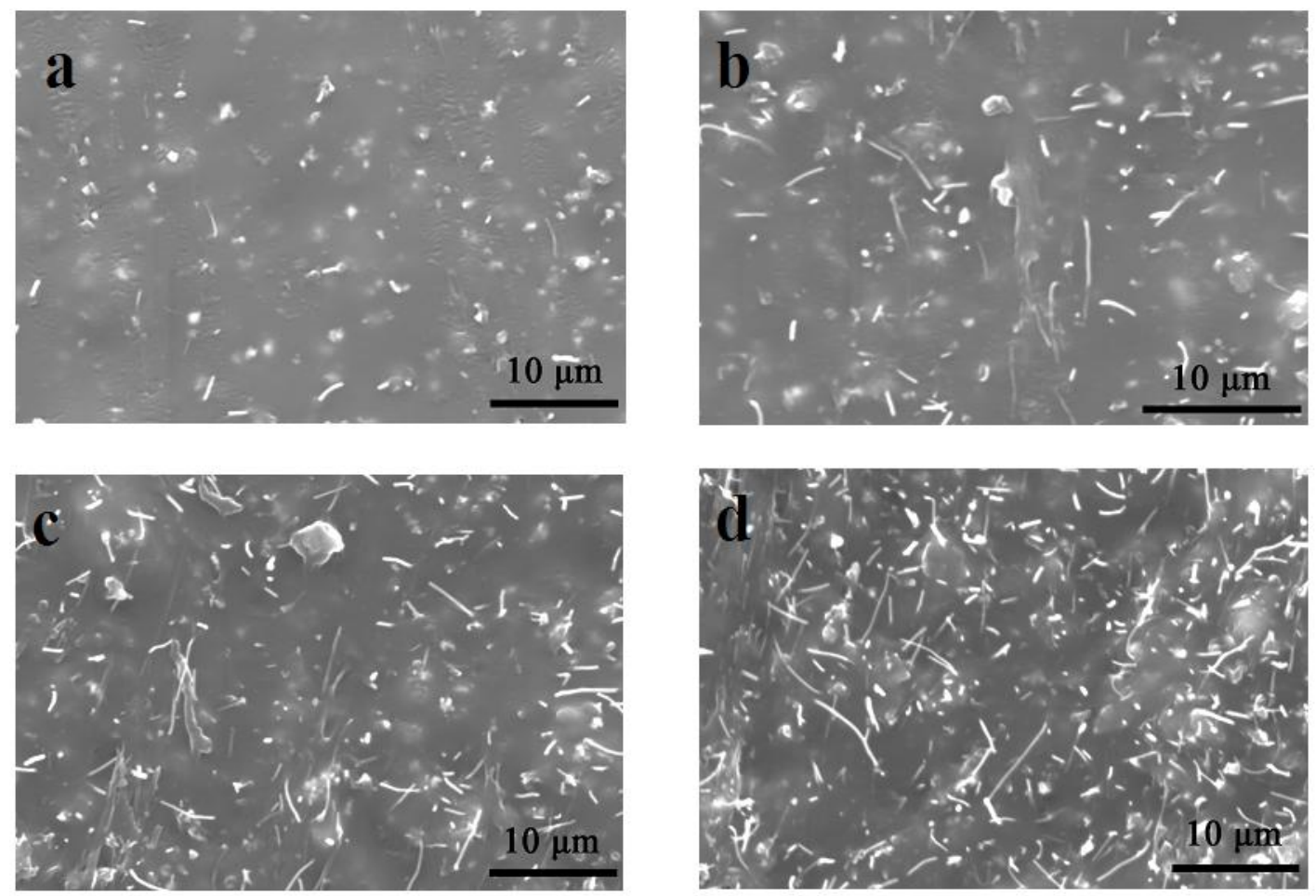

Fig. 3. 


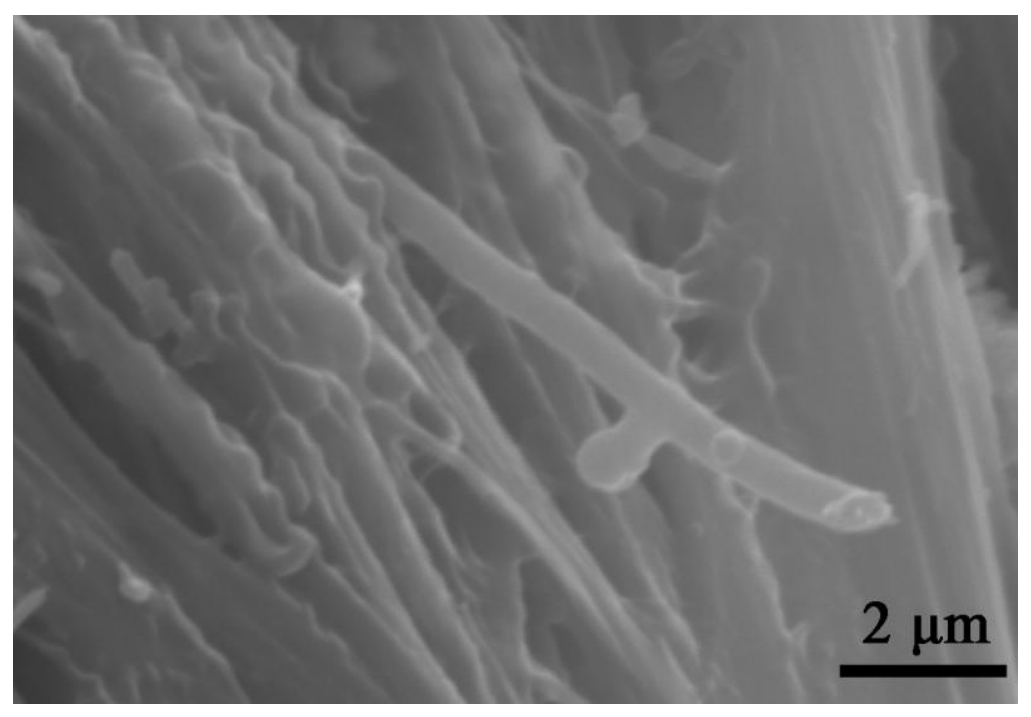

Fig. 4. 


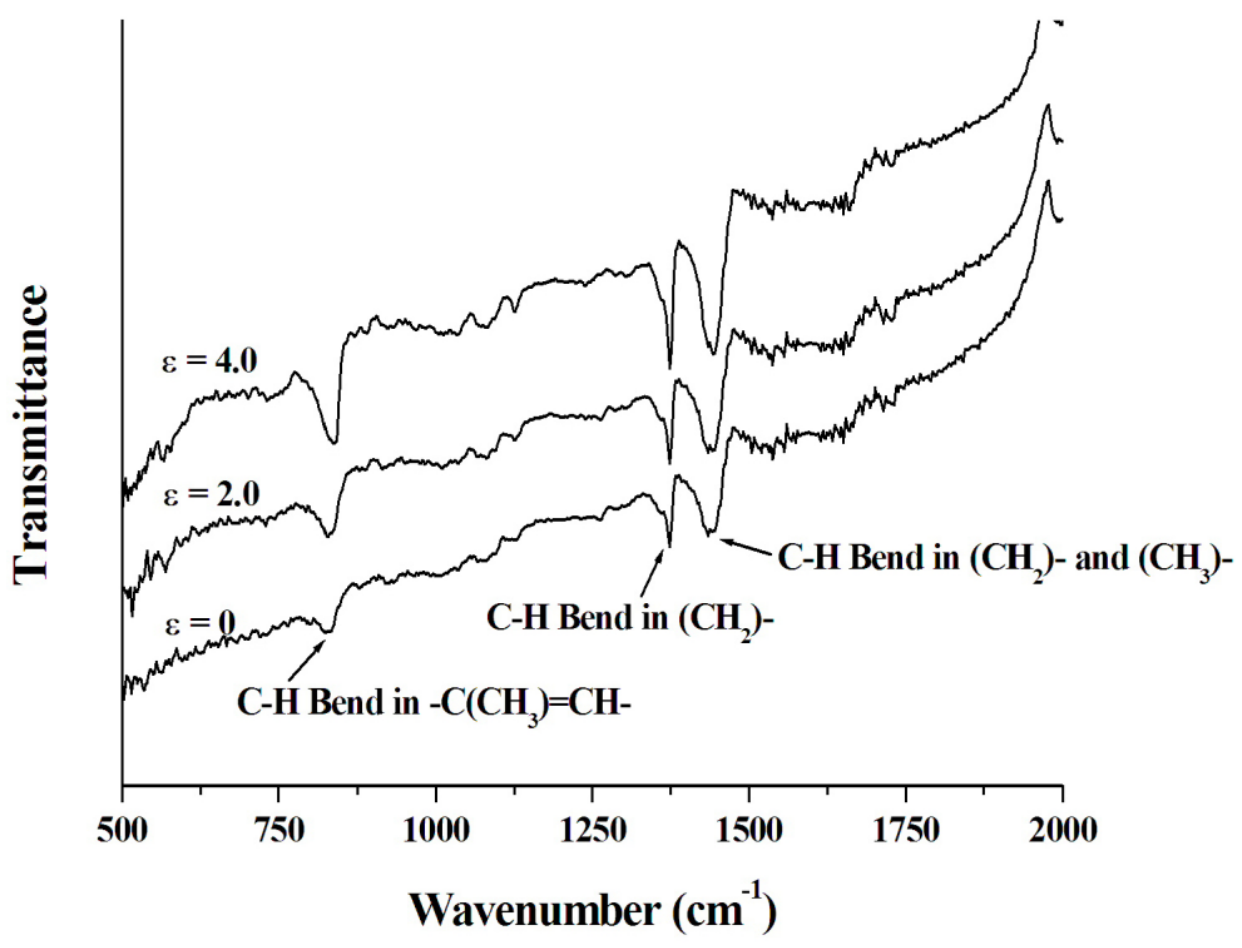

Fig. 5. 


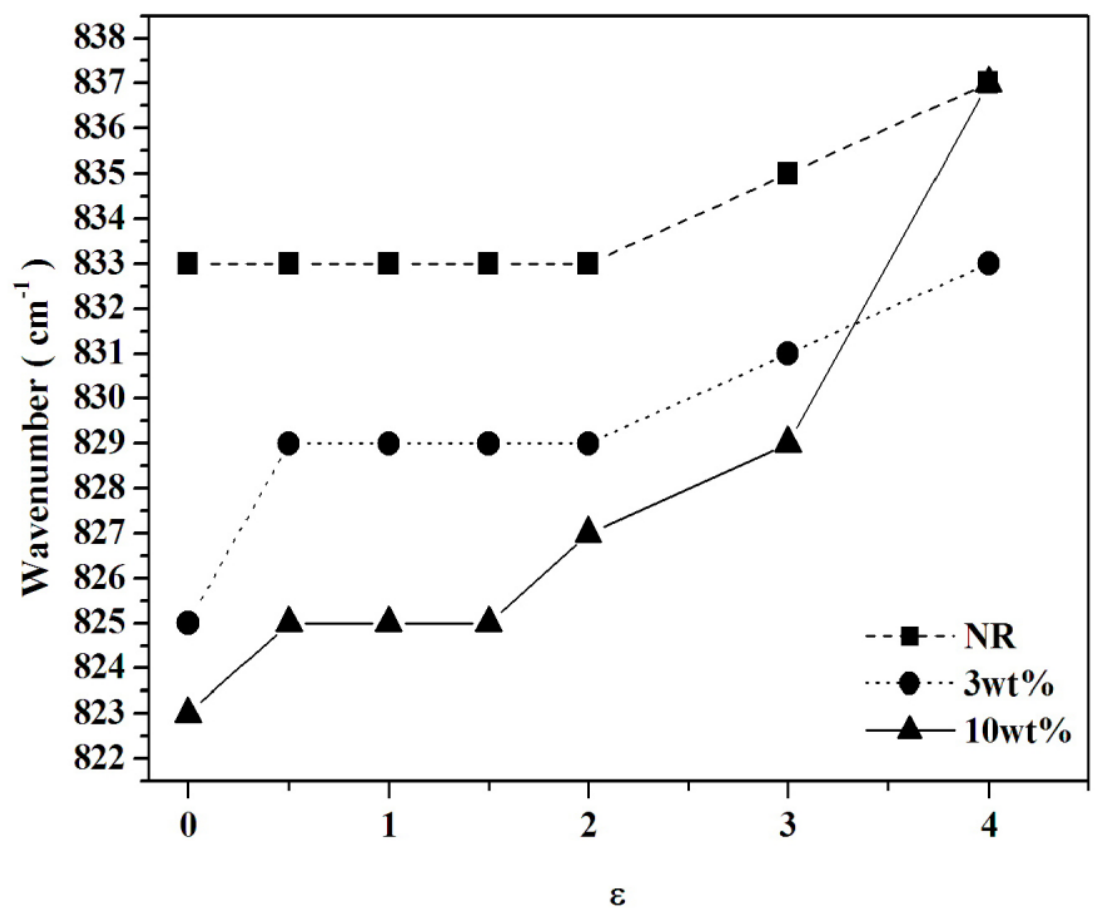

Fig. 6. 


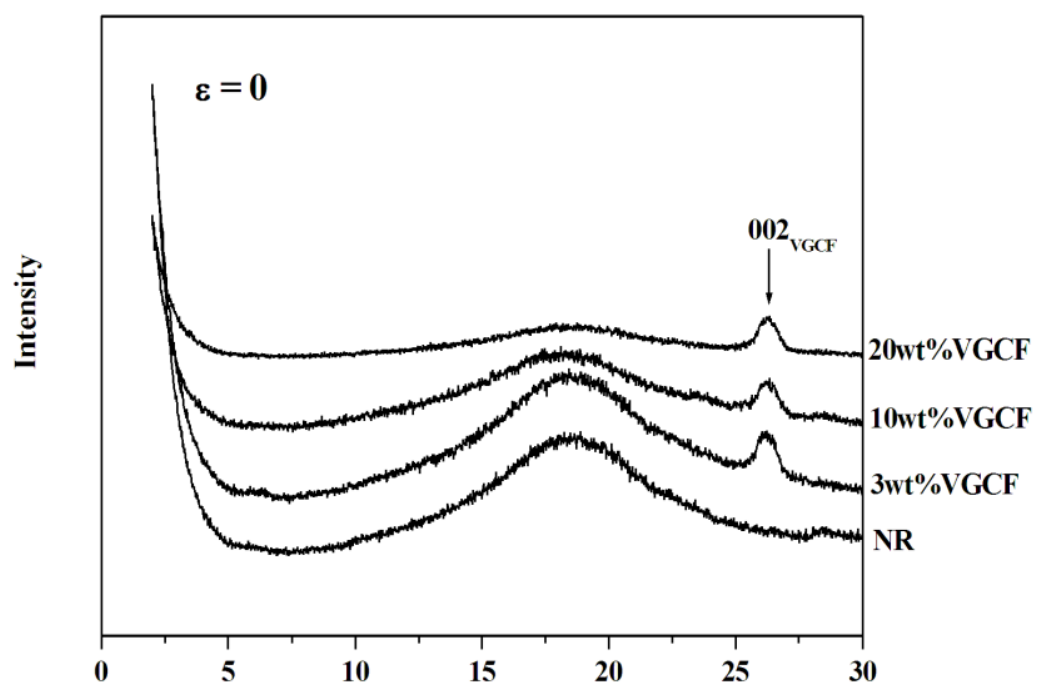

(a)

$2 \theta\left({ }^{\circ}\right)$

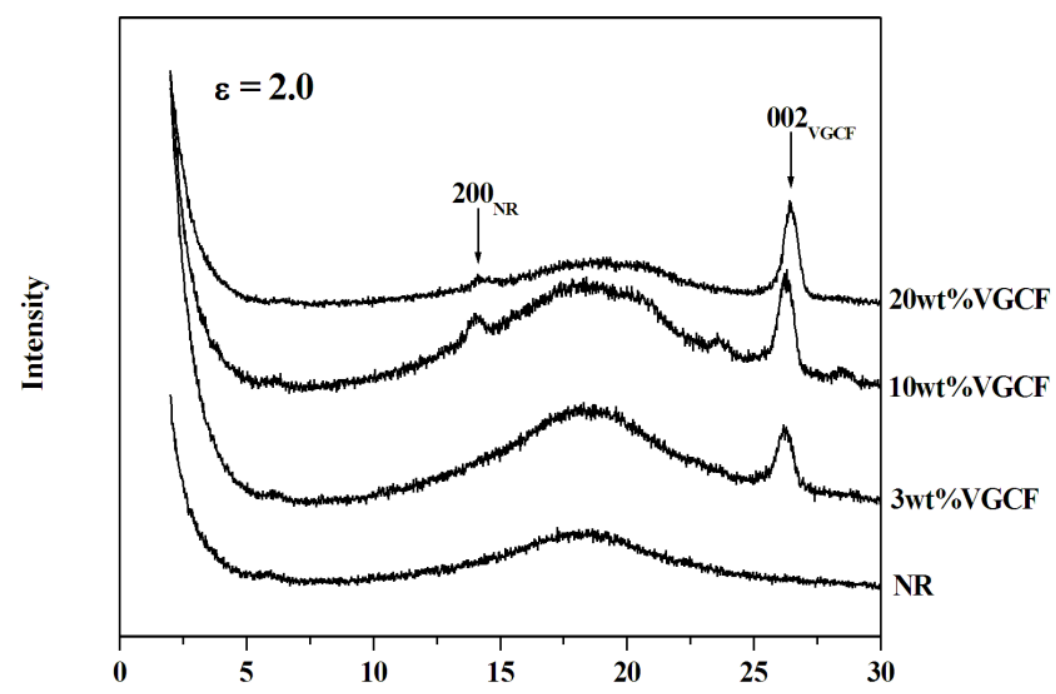

(b)

$2 \theta\left({ }^{\circ}\right)$

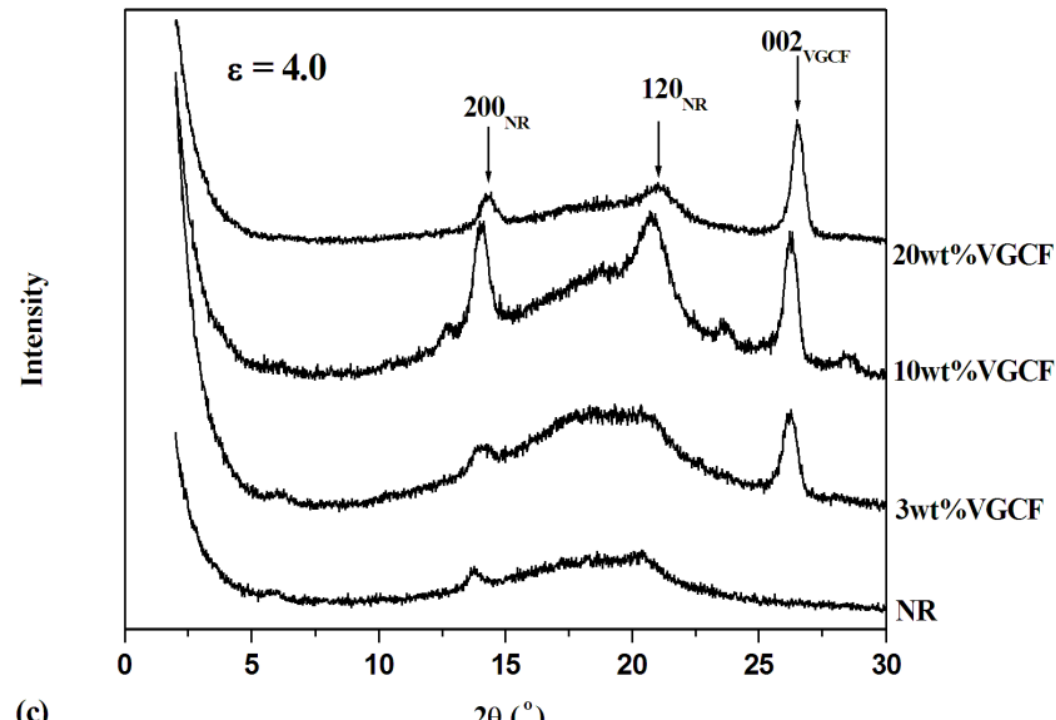

(c)

$2 \theta\left(^{\circ}\right)$

Fig. 7. 